\title{
Meme Cerrahisi ve Aksiller Diseksiyon Uygulanan Meme Kanserli Hastalarda Üst Ekstremite Problemlerinin Sıklığı ve Yașam Kalitesine Etkisi
}

\section{The Presence of Upper Extremity Problems and the Effect on Quality of Life in Breast Cancer Patients who Undergone Breast Surgery and Axillary Dissection}

\author{
Nilgün ŞIMŞIR ATALAY, Selin TAFLAN SELÇUK*, Özlem ERCIDOĞAN, Nuray AKKAYA, Ayşe SARSAN, Arzu YAREN**, Füsun ŞAHIN \\ Pamukkale Üniversitesi Tıp Fakültesi, Fizik Tedavi ve Rehabilitasyon Anabilim Dalı, Denizli, Türkiye \\ *Ankara Onkoloji Eğitim ve Araştırma Hastanesi, Fizik Tedavi ve Rehabilitasyon Kliniği, Ankara, Türkiye \\ **Pamukkale Üniversitesi Tıp Fakültesi, Medikal Onkoloji Anabilim Dalı, Denizli, Türkiye
}

\section{Özet}

Amaç: Bu çalışmanın amacı meme kanseri nedeniyle cerrahi uygulanan hastalarda üst ekstremite problemlerinin görülme sıklığının saptanması, bu problemlerle ilişkili risk faktörlerinin karşılaştırılması ve yaşam kalitesi üzerine etkilerini araştırmaktır.

Gereç ve Yöntem: Modifiye radikal mastektomi veya meme koruyucu cerrahi (lumpektomi) uygulanan 132 hasta çalışmaya dahil edildi. Üst ekstremite problemleri olarak lenfödem, omuz ağrısı, omuz hareket kısıtıılığı değerlendirildi. Ayrıca operasyon şekli, vücut kitle indeksi (VKi), kemoterapi $(\mathrm{KT})$, radyoterapi (RT), hastalık evresi, lenf nodu tutulumu, yaş, dominant elin tutulumu kaydedildi. Yaşam kalitesi ölçeği olarak Dünya Sağlık Örgütü Yaşam Kalitesi Ölçeği Türkçe kısa formu (WHOQOL-BREF TR) kullanıldı.

Bulgular: Hastalarda en sık görülen semptom olan omuzda ağrıyı $(\% 45,5)$, lenfödem $(\% 34,8)$ ve omuzda hareket kısıtlılı̆ı $(\% 22)$ takip etmekteydi. Yaş, operasyon şekli, omuzda hareket kısıtlııı̆ı, ağıı varlığı ve dominant elin tutulumu ile lenfödem arasında anlamlı ilişki saptanmazken, artmış VKI, KT-RT tedavisi almış olma, ileri hastalık evresi, lenf nodu tutulumu varlığı lenfödem olan grupta daha yüksekti $(p<0,05)$. Düzenli egzersiz yapmanın lenfödem, ağrı ve hareket kısıtılığını azaltma yönünde etkili bir faktör olduğu görüldü $(p<0,05)$. Lenfödem, ağrı ve omuz hareket kısıtlılı̆ının WHOQOL-BREF TR'nin bedensel, ruhsal alt alanları üzerine, omuz hareket kıııtlılı̆ının ayrıca çevre alt alanı üzerine de etkili olduğu gösterildi $(p<0,05)$. Lenfödem, ağrı ve omuz hareket kısıtlılığının hangisinin yaşam kalitesi üzerine daha etkili olduğuna

\section{Summary}

Aim: The purpose of this study was to determine the prevalence of upper extremity problems in patients who had undergone breast cancer surgery, to compare the risk factors associated with these problems and to investigate their effects on quality of life.

Materials and Methods: One hundred thirty-two patients who had undergone either modified radical mastectomy or breast conserving surgery (lumpectomy) were enrolled to the study. Lymphedema, shoulder pain and restriction of shoulder motion were considered as upper extremity problems. Type of surgery, body mass index (BMI), radiotherapy, chemotherapy, disease stage and dominant hand involvement were recorded. The World Health Organisation (WHO) Quality of Life-BREF-Turkish Version (WHOQOLBREF-TR) was used for the assessment of quality of life.

Results: Shoulder pain was the most common symptom (45.5\%), followed by lymphedema (34.8\%) and shoulder motion restriction (22\%). No significant relation was found between lymphedema and age, type of surgery, restriction of shoulder motion, pain and dominant hand involvement. Increased $\mathrm{BMI}$, treatment with chemotherapy or radiotherapy, advanced-disease stage and lymph node involvement were associated with lymphedema $(p<0.05)$. It was seen that doing regular exercise had positive effect on lymphedema, pain and shoulder motion restriction reduction $(p<0.05)$. Lymphedema, pain and shoulder motion restriction were related with physical and psychological subgroups of WHOQOL-BREF TR, whereas shoulder motion restriction was also associated with the environmental subgroup $(p<0.05)$. When 
baktığımızda omuz ağrısının bedensel ve ruhsal alana, kısıtlılığın bedense alan üzerine en etkili olduğu, lenfödemin ise yaşam kalitesi alt alanlarında etkisinin olmadığı gösterildi. Ayrıca egzersizin yaşam kalitesinin ruhsal ve çevre alanı üzerine olumlu katkısı bulundu $(p<0,05)$.

Sonuç: Meme cerrahisi sonrası kol problemleri sık görülmekte olup, hastaların günlük yaşamlarını etkileyip hayat kalitelerini düşürmektedir. Bu hastalarda koruyucu önlemlerin alınması ve düzenli takip ile komplikasyonların en aza indirilerek hastaların yaşam kalitesinin korunmas temel hedef olmalıdır. Türk Fiz Tıp Rehab Derg 2011;57:186-92.

Anahtar Kelimeler: Meme kanseri, lenfödem, ağrı, omuzda kısıtlııı, yaşam kalitesi lymphedema, pain and shoulder motion restriction was searched for to determine which one was more effective on quality of life shoulder pain had negative effect in the physical and psychological subgroups; motion restriction had negative effect in the physical subgroup, whereas lymphedema did not affect the quality of life subgroups. Exercise also had positive contribution to environmental and psychological subgroups of quality of life $(p<0.05)$.

Conclusion: Arm problems are frequently encountered following breast surgery and affect the daily living of patients by decreasing their quality of life. The major aim in these patients must be taking preventive precautions and preserving the quality of life by minimizing complications with regular follow-up. Turk J Phys Med Rehab 2011;57:186-92.

Key Words: Breast cancer, lymphedema, pain, shoulder restriction, quality of life

\section{Giriş}

Meme kanseri dünyada kadınlar arasında en sık görülen kanser türü olup Amerika'da kadın cinsiyet için tüm ölümlerin yaklaşık \%15'ini oluşturmaktadır. Cerrahi, kemoterapi (KT), radyoterapi (RT) ve hormonal tedaviyi içeren meme kanseri tedavisi hastanın sonuçlarını düzeltse de birçok komplikasyonla ilişkilidir (1). Meme kanserine yönelik bölgesel tedavi lenfödem, omuzda ağrı ve hareket kısıtlılığı ile sonuçlanabilmektedir. Tanıdan beş yıla kadar olan takiplerde \%38 hastada kol problemleri mevcut olup (2), hastaların günlük yaşamları önemli derecede etkilenmekte ve bu hastalarda yaşam kalitesi daha düşük bulunmaktadır (3).

Meme kanseri tedavisi sonrası lenfödem insidansı uygulanan tedaviye, lenfödem tanımlama kriterlerine ve takip süresine göre değişmekle birlikte beş yıllık izlemde lenfödem insidansı \%42 oranında bulunurken (4), üç yıllık izlemde \%15 ile \%54 arasında değişmektedir $(5,6)$. Omuz ağrısı \%38,5 ile \%76,1 arasında değişen oranlarda olup, genellikle hastaların en sık yakınmasıdır (7-9). Cerrahiden sonra bir yıla kadar meme kanserli hastaların \%1643'ünde omuz fonksiyon bozukluğu olduğu belirtilmiştir (10).

Meme kanseri tedavisine sekonder gelişen kol problemleri, hastalarda daha çok fonksiyonel bozukluk, psikolojik morbidite ve bozulmuş hayat kalitesine neden olmaktadır (7,9,11-14). Ağrı, uyuşukluk ve omuzda kısıtlılık birbirinden bağımsız olarak oluşabileceği gibi, birbiriyle ilişkili veya lenfödemin sonucu olarak da ortaya çıkabilmektedir (15).

Modern tedavi seçenekleri sayesinde meme kanserli hastalarda sağ kalım süresi artmakla birlikte, sağlıkla ilişkili hayat kalitesi daha önemli bir konu haline gelmektedir $(7,9,16)$.

Yapılan literatür taramasında, üst ekstremiteye ait semptomatolojiler olan lenfödem, omuzda ağrı ve omuzda hareket kısıtııı̆̆ının yaşam kalitesi üzerine etkisini farklı ölçeklerle araştıran çalışmalar olmakla birlikte $(3,7,9,14)$ WHOQOL-BREF TR ile yaşam kalitesi üzerine etkisini araştıran çalışmaya rastlanmamıştır.

Bu çalışmada amaçlarımız: (1) Meme cerrahisi ve aksiller diseksiyon uygulanan hastalarda lenfödem, omuz ağrısı ve omuzda hareket kısıtlılı̆ı görülme sıklığının saptanması, (2) Lenfödem, omuzda ağrı ve kısıtlılığı olan ve olmayan hastaların demografik ve klinik özellikleri ve tedavi şekillerinin karşılaştırılması, (3) Bu hastalarda demografik, klinik ve tedavi parametrelerinin WHOQOL-BREF TR ile yaşam kalitesi üzerine etkisini araştırmaktır.

\section{Gereç ve Yöntem}

Bu çalışma iki merkezli olarak Fizik Tedavi ve Rehabilitasyon polikliniğine başvuran hastalarla yapılmıştır. Çalışmaya; meme kanseri nedeniyle cerrahi (modifiye radikal mastektomi veya meme koruyucu cerrahi-lumpektomi) ve aksiller diseksiyon uygulanmış, cerrahi sonrası en az üç ay geçmiş, hastalık evresi 1-3 arasında olan hastalar çalışmaya dahil edildi. Çalışmadan dışlanma kriterleri; bilateral mastektomi, lokal rekürrens, uzak metastaz ve kognitif durum bozukluğu olarak belirlendi.

Bütün hastalarda boy $(\mathrm{cm})$, kilo $(\mathrm{kg})$, yaş (yıl), hastalık evresi $(1,2,3)$, operasyon şekli (1-Modifiye radikal mastektomi-MRM, 2Meme koruyucu cerrahi-MKC), operasyon sonrası geçen süre (ay), tutulan taraf (sağ-sol), dominant el (sağ-sol), dominant elin tutulan taraf olması, lenf nodu tutulumu (1-var, 2-yok), uygulanan tedavi (1-KT, 2-RT), operasyon sonrası etkilenen ekstremiteye yönelik egzersiz tedavisi (1-var, 2-yok) sorgulandı.

Hastaların üst ekstremite problemleri (1-yok, 2-lenfödem, 3omuz ağrısı, 4-omuz eklem kısıtlılığı) belirlendi.

Lenfödem varlığı için kemik çıkıntılara göre çevresel ölçüm (cm) yapıldı. Lateral epikondilin $15 \mathrm{~cm}$ proksimali, $10 \mathrm{~cm}$ distali, el bileği ve metakarpofalangeal eklemden çevresel ölçüm yapılarak kontralateral ekstremite ile $2 \mathrm{~cm}$ 'den fazla fark olması lenfödem pozitifliği olarak değerlendirildi (17).

Omuz ağrısı sorgulanan hastalarda ağrı olup olmadığı sorgulandıktan sonra ağrı olduğunu belirten grupta ağrı değerlendirmesi 10 cm'lik görsel ağrı değerlendirme skalası (GAS) ile istirahat ağrısı ölçülerek yapıldı.

Omuz eklem hareket açıklıkları her iki ekstremitede fleksiyon ve abduksiyon planlarında gonyometre ile derece cinsinden ölçüldü. Kontralateral ekstremite ile 25 derece ve üzeri fark olan hastalarımız omuz kısıtıılı̆ı pozitif olarak kaydedildi.

Hastaların yaşam kaliteleri Dünya Sağlık Örgütü Yaşam Kalitesi Ölçeği Türkçe kısa formu (WHOQOL-BREF TR) kullanılarak değerlendirildi. Bu ölçek 26 soru ve 4 alanı kapsamaktadır. Bu 4 alan bedensel ( 7 madde), ruhsal ( 6 madde), sosyal ( 3 madde), çevre ( 8 madde) alanlarını içermektedir. Bedensel alanda, gündelik işleri yürütebilme, ilaçlara ve tedaviye bağımlılık, hareketlilik, ağrı, uyku ve dinlenme, çalışabilme gücü ile ilgili sorular yer almaktadır. Ruhsal alan, olumlu ve olumsuz duygular, benlik saygısı, dış görünüş, kişisel inançlar, dikkatini toplama; sosyal alanı ise diğer kişilerle ilişkiler, sosyal destek ve cinsel yasam ile ilgili sorulardan oluşmaktadır. Çevre alanında ev ortamı, fiziksel güvenlik ve emniyet, maddi kaynaklar, 
sağlık hizmetleri, ulaşılabilirlik, boş zamanları değerlendirme fırsatları, fiziksel çevre ve ulaşım ile ilgili sorular bulunmaktadır. Alan puanları 420 arasında ve 0-100 arasında ayrı ayrı hesaplanabilmektedir. Alan puanları yükseldikçe yaşam kalitesinin yükseldiği gösterilmektedir. Ölçeğe ait bir toplam puan hesaplanmamaktadır. Bu çalışmada 4-20 arası puanlar kullanılmıştır. Türkçe formunun geçerlik ve güvenilirliği Eser ve ark. tarafından yapılmıştır $(18,19)$.

İstatistiksel değerlendirme "SPSS 17.0 for Windows software paket programı" kullanılarak yapıldı. İstatistiksel analizlerde kategorik veriler için Ki-kare testi, sayısal verilerin gruplar arasında karşılaştırılmasında bağımsız gruplarda t test kullanıldı. Tekli analizlerde anlamlı bulunan değişkenlerden oluşturulan bir model ile çoklu analiz uygulandı. Bu amaçla lojistik regresyon analizi kullanıldı. Çoklu analizde yaşam kalitesinin alt alanları (bedensel, ruhsal, sosyal, çevre) dikotom haline dönüştürüldü ve bu dönüştürmede kesme noktası olarak ortanca değer esas alındı. Kesme noktalarımız bedensel alan için 14, ruhsal alan için 14 , sosyal alan için 13, çevre alanı için 15 olarak saptandı. Benzer şekilde VKi dikotom haline dönüştürüldü ve bu dönüştürmede ise $25 \mathrm{~kg} / \mathrm{m}^{2}$-(aşırı kilolu) esas alındı. İstatistiksel anlamlılık düzeyi $\mathrm{p}<0,05$ olarak kabul edildi.

\section{Bulgular}

Çalışmaya meme cerrahisi ve aksiller diseksiyon uygulanan

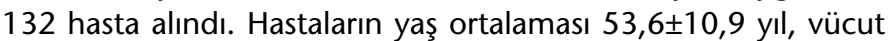
kitle indeksi (VKi) $29,9 \pm 5,3 \mathrm{~kg} / \mathrm{m}^{2}$ idi. Cerrahi sonrası geçen süre $31,8 \pm 38,8$ (3-148) ay idi. Hastalarda en sık görülen semptom

Tablo 1. Hastaların klinik ve tedavi özellikleri.

\begin{tabular}{|c|c|}
\hline $\begin{array}{c}\text { Operasyon şekli, } \mathrm{n}(\%) \\
\text { MRM+AD }\end{array}$ & $118(89,4)$ \\
MKC+AD & $14(10,6)$ \\
\hline Evre, $\mathrm{n}(\%)$ & $16(12,1)$ \\
1 & $64(48,5)$ \\
2 & $52(39,4)$ \\
3 & \\
\hline Tutulan taraf, $\mathrm{n}(\%)$ & $60(45,5) / 72(54,5)$ \\
sağ /sol & $59(44,7)$ \\
\hline Dominant elin tutulumu, $\mathrm{n}(\%)$ & $109(82,6)$ \\
\hline Adjuvan tedavi, $\mathrm{n}(\%)$ & $80(60,6)$ \\
\hline KT & $86(65,2)$ \\
$\mathrm{RT}$ & $46(34,8)$ \\
\hline Lenf nodu tutulumu, $\mathrm{n}(\%)$ & $60(45,5)$ \\
\hline Lenfödem, $\mathrm{n}(\%)$ & $29(22,0)$ \\
\hline Omuzda ağrı, $\mathrm{n}(\%)$ & $73(55,3)$ \\
\hline Omuzda kısıtlıık, $\mathrm{n}(\%)$ & \\
\hline Egzersiz yapanlar, $\mathrm{n}(\%)$ & \\
\hline Yaşam kalitesi & $13,74 \pm 3,18$ \\
WHOQOL-BREF TR (ort \pm SS) & $13,56 \pm 2,49$ \\
Bedensel alan & $13,33 \pm 3,10$ \\
Ruhsal alan & $14,51 \pm 2,22$ \\
Sosyal alan & \\
Çevre alanı & \\
\hline
\end{tabular}

MRM: Modifiye radikal mastektomi

MKC: Meme koruyucu cerrahi

AD: Aksiller diseksiyon

KT: Kemoterapi

RT: Radyoterapi olan omuzda ağrıyı $(\% 45,5)$, lenfödem $(\% 34,8)$ ve omuzda hareket kısıtlıı̆ı (\%22) takip etmekteydi. Hastaların demografik, klinik ve tedavi özellikleri Tablo 1'de verilmiştir.

Hastaların \%34,8'inde lenfödem mevcuttu. Lenfödem ile ilişkili demografik ve klinik faktörler incelendiğinde yaş, operasyon şekli, omuzda hareket kısıtlılı̆ı, ağrı varlığı ve dominant elin tutulumu ile arasında anlamlı ilişki saptanmazken, artmış VKI, KT-RT tedavisi almış olma, ileri hastalık evresi, lenf nodu tutulumu varlığı lenfödem olan grupta daha yüksekti $(p<0,05)$. Operasyon sonrası egzersiz yapanların $\% 79,5^{\prime}$ inde lenfödem gözlenmezken, \%20,5'inde lenfödem mevcuttu ve fark istatistiksel olarak anlamlıydı $(p<0,05)$. Lenfödem olan ve olmayan hastaların demografik ve klinik şekillerinin karşılaştırılması Tablo 2'de verilmiştir.

Hastaların \%45,5'inde omuz ağrısı, \%22'sinde omuzda hareket kısıtııı̆ı mevcuttu. Aynı demografik, klinik ve tedavi parametreleri ile omuzda ağı ve hareket kısıtılığı arasındaki ilişkiyi karşılaştırdığımızda her iki semptom ile sadece egzersiz yapanlar arasında istatistiksel ilişki saptanırken diğer parametrelerle anlamlı ilişki saptanmadı. Her iki semptom da sadece düzenli egzersiz yapanlarda anlamlı olarak daha az saptandı. Egzersiz yapanların \%63'ünde omuzda ağrı bulunmazken, \%37'sinde ağrı vardı, yine egzersiz yapanların \%89'unda omuzda kısıtılık bulunmazken, $\% 11$ 'inde kısıtlılık mevcuttu $(p<0,05)$.

Tüm hastaların WHOQOL-BREF TR bedensel, ruhsal, sosyal ve çevre alanları değerleri Tablo 1'de gösterilmiştir. Bedensel alan ile operasyon tipi, lenfödem varlığı, omuzda ağrı ve kısıtlılık varlığı arasında anlamlı ilişki görüldü. Omuzda ağrı, kısıtlıık ve tutulan tarafta lenfödemin olmadığı, operasyon tipinin MKC olduğu hastalarda bedensel alan değerinin anlamlı olarak yüksek olduğu saptandı $(p<0,05)$. Ruhsal alan ile operasyon tipi, omuzda kısıtılık,

Tablo 2. Lenfödem olan ve lenfödem olmayan hastaların demografik, klinik ve tedavi şekillerinin karşılaştırılması.

\begin{tabular}{|c|c|c|c|}
\hline & Lenfödem (-) & Lenfödem (+) & p \\
\hline Yaş (yıl) Ortt+SS & $53,10 \pm 10,31$ & $54,65 \pm 12,23$ & $p>0,05$ \\
\hline VKI $\left(\mathrm{kg} / \mathrm{m}^{2}\right)$ Ort $\pm S S$ & $29,19 \pm 5,53$ & $31,36 \pm 4,58$ & $p<0,05$ \\
\hline KT (\%) & 76,7 & 93,5 & $p<0,05$ \\
\hline RT (\%) & 51,2 & 84,8 & $p<0,001$ \\
\hline \multicolumn{4}{|l|}{ Evre, (\%) } \\
\hline 1 & 16,3 & 4,3 & \\
\hline 2 & 51,2 & 43,5 & $p<0,05$ \\
\hline 3 & 32,6 & 52,2 & \\
\hline \multicolumn{4}{|l|}{ Operasyon şekli, \% } \\
\hline $\mathrm{MRM}+\mathrm{AD}$ & 64,4 & 35,6 & $p>0,05$ \\
\hline $\mathrm{MKC}+\mathrm{AD}$ & 71,4 & 28,6 & \\
\hline Dominant elin tutulumu, \% & 66,1 & 33,9 & $p>0,05$ \\
\hline Omuzda ağrı, \% & 58,3 & 41,7 & $p>0,05$ \\
\hline Omuzda kısıtlılık, \% & 62,1 & 37,9 & $p>0,05$ \\
\hline Lenf nodu tutulumu, \% & 57,0 & 80,4 & $p<0,05$ \\
\hline Egzersiz yapanlar, \% & 79,5 & 20,5 & $p<0,001$ \\
\hline
\end{tabular}

VKi: Vücut kitle indeksi

KT: Kemoterapi

RT: Radyoterapi

MRM: Modifiye radikal mastektomi

MKC: Meme koruyucu cerrahi

AD: Aksiller diseksiyon 
ağrı, lenfödem varlığı ve egzersiz arasında anlamlı ilişki görüldü. Operasyon tipinin MKC olduğu, lenfödem, omuzda ağrı ve kısıtlıık olmayan hastalarda ruhsal alan değeri anlamlı olarak yüksekti $(p<0,05)$. Sosyal alan ile egzersiz arasında anlamlı ilişki varken, çevre alanı ile KT, omuzda hareket kısıtııı̆ı ve egzersiz arasında anlamlı ilişki görüldü. Egzersiz uygulayan hastalarda ruhsal, sosyal ve çevre alan değerleri anlamlı olarak yüksekti $(p<0,05)$. KT almayan, omuzda hareket kısıtlıı̆ı olmayan hastaların çevre alan değerlerinin anlamlı olarak yüksek olduğu saptandı $(p<0,05)$. VKI yüksek olan hastaların bedensel ve çevre alan değerleri daha düşüktü $(p<0,05)$. Hastaların klinik, demografik ve tedavi özelliklerine göre yaşam kalitesi alt alanlarının ortalama değerleri ve karşılaştırmaları Tablo 3'te gösterilmiştir.

Bağımsız gruplarda $\mathrm{t}$ test ile anlamlı bulduğumuz değişkenlerden (VKI, KT, egzersiz, lenfödem, omuzda ağrı ve kısıtlılık) oluşan bir model hazırlandı ve bu modele enter metoduyla lojistik regresyon analizi uygulandı. Yaşam kalitesi ölçeği alt alanları ile karşılaştırma yapıldığında bedensel alanın omuzda ağrıdan (Odds Ratio (OR):5,18, \%95 Güven aralığı (GA):2,27-11,78) ve kısıtlılıktan (OR:3,93, \%95 GA:1,24-12,39); ruhsal alanın omuzda ağrıdan (OR:3,07, \%95 GA:1,39-6,78) ve egzersiz yapma alışkanlığından (OR:0,41, \%95 GA:0,18-0,97); çevre alanının ise egzersiz yapma alışkanlığından (OR:0,29, \%95 GA:0,11-0,75) etkilendiği saptandı (Tablo 4).

\section{Tartışma}

Meme kanserinde tedavi tekniklerinin ilerlemesiyle birlikte sağ kalım oranları dramatik bir şekilde artmakta ve $A B D^{\prime}$ de 2,2 milyonun üzerinde meme kanserli hasta bulunmaktadır (20). Giderek artan meme kanserli kadın sayısı ile birlikte tedavi yan etkilerinin morbiditesini saptamak ve azaltmak yüksek önceliğe sahip olup son yıllarda araştırmaların odağı haline gelmiştir (21).

Çalışmamızın sonuçlarına göre; meme cerrahisi ve aksiller diseksiyon uygulanan hastalarda kol morbiditesi semptomlarından ağrı en sık görülen semptomdur. Lenfödemli hastaların daha yüksek VKI ve hastalık evresi olduğu, daha fazla RT, KT alma oranı mevcuttur. Düzenli egzersiz yapma ağrı, hareket kısıtlılığı ve lenfödemin tümünün üzerine etkili bir faktördür. Lenfödem, ağrı ve hareket kısıtılığı olan hastaların yaşam kalitesinin pek çok alanında daha düşük skorlara sahip olduğu belirlenmiş olup, en olumsuz etkileyen faktörlerin omuz ağrısı ve hareket kısıtlılı̆ı olduğu ve egzersiz yapmamanın da olumsuz etkileri olduğu belirlenmiştir.

Meme kanseri cerrahisinde uygulanan aksiller lenf nodu diseksiyonu, ağrı, lenfödem, azalmış omuz eklem hareket açıklığı ile ilişkilidir $(3,9,11,13,15,22-24)$. Bu nedenle sentinel lenf nodu biyopsi tekniğinin erken evre meme kanserinde yaygın kullanımıyla morbidite oranlarını düşürmek amaçlanmaktadır.

Tablo 3. Hastaların klinik, demografik ve tedavi özelliklerine göre yaşam kalitesi alt alanlarının ortalama değerleri ve karşılaştırmaları.

\begin{tabular}{|c|c|c|c|c|c|c|c|c|}
\hline & \multicolumn{2}{|c|}{ Bedensel alan } & \multicolumn{2}{|c|}{ Ruhsal alan } & \multicolumn{2}{|c|}{ Sosyal alan } & \multicolumn{2}{|c|}{ Çevre alanı } \\
\hline & ort $\pm S S$ & $p$ & ort $\pm S S$ & $p$ & ort $\pm S S$ & $p$ & ort $\pm S S$ & $p$ \\
\hline \multicolumn{9}{|l|}{ Operasyon tipi } \\
\hline$M K C+A D$ & $15,64 \pm 1,98$ & 0,018 & $14,85 \pm 1,40$ & 0,040 & $14,00 \pm 1,61$ & 0,398 & $15,14 \pm 1,65$ & 0,265 \\
\hline $\mathrm{MRM}+\mathrm{AD}$ & $13,52 \pm 3,23$ & & $13,40 \pm 2,55$ & & $13,25 \pm 3,23$ & & $14,44 \pm 2,27$ & \\
\hline \multicolumn{9}{|l|}{ KT } \\
\hline var & $13,64 \pm 3,11$ & 0,434 & $13,44 \pm 2,54$ & 0,268 & $13,15 \pm 3,18$ & 0,154 & $14,31 \pm 2,23$ & 0,022 \\
\hline yok & $14,21 \pm 3,55$ & & $14,08 \pm 2,25$ & & $14,17 \pm 2,56$ & & $15,47 \pm 1,92$ & \\
\hline \multicolumn{9}{|l|}{ RT } \\
\hline var & $13,80 \pm 2,98$ & 0,762 & $13,61 \pm 2,40$ & 0,749 & $13,30 \pm 3,06$ & 0,878 & $14,25 \pm 2,24$ & 0,078 \\
\hline yok & $13,63 \pm 3,53$ & & $13,46 \pm 2,67$ & & $13,38 \pm 3,20$ & & $14,95 \pm 2,13$ & \\
\hline \multicolumn{9}{|l|}{ Lenf nodu tut. } \\
\hline var & $13,73 \pm 3,24$ & 0,961 & $13,55 \pm 2,48$ & 0,988 & $13,39 \pm 3,21$ & 0,755 & $14,31 \pm 2,22$ & 0,156 \\
\hline yok & $13,76 \pm 3,10$ & & $13,56 \pm 2,55$ & & $13,21 \pm 2,91$ & & $14,89 \pm 2,19$ & \\
\hline \multicolumn{9}{|l|}{ Lenfödem } \\
\hline var & $12,91 \pm 3,18$ & 0,028 & $12,73 \pm 2,48$ & 0,005 & $13,04 \pm 3,43$ & 0,435 & $14,21 \pm 2,30$ & 0,262 \\
\hline yok & $14,18 \pm 3,11$ & & $14,00 \pm 2,40$ & & $13,48 \pm 2,92$ & & $14,67 \pm 2,17$ & \\
\hline \multicolumn{9}{|l|}{ Ağrı } \\
\hline var & $12,23 \pm 2,86$ & 0,000 & $12,81 \pm 2,45$ & 0,002 & $13,16 \pm 3,02$ & 0,575 & $14,38 \pm 2,17$ & 0,536 \\
\hline yok & $15,00 \pm 2,90$ & & $14,18 \pm 2.38$ & & $13,47 \pm 3,18$ & & $14,62 \pm 2,26$ & \\
\hline \multicolumn{9}{|l|}{ Kısıtlıık } \\
\hline var & $12,27 \pm 3,29$ & 0,005 & $12,37 \pm 2,66$ & 0,004 & $12,68 \pm 2,84$ & 0,208 & $13,41 \pm 2,29$ & 0,002 \\
\hline yok & $14,15 \pm 3,04$ & & $13,89 \pm 2,35$ & & $13,51 \pm 3,16$ & & $14,82 \pm 2,11$ & \\
\hline \multicolumn{9}{|l|}{ Egzersiz } \\
\hline var & $14,12 \pm 3,38$ & 0,127 & $14,15 \pm 2,58$ & 0,002 & $13,89 \pm 2,87$ & 0,021 & $15,05 \pm 2,16$ & 0,002 \\
\hline yok & $13,27 \pm 2,88$ & & $12,83 \pm 2,19$ & & $12,64 \pm 3,25$ & & $13,84 \pm 2,12$ & \\
\hline
\end{tabular}

MRM: Modifiye radikal mastektomi

MKC: Meme koruyucu cerrahi

AD: Aksiller diseksiyon

KT: Kemoterapi

RT: Radyoterapi 
Çalışmamızda hastalarımızın tümünde aksiller lenf nodu diseksiyonu uygulanmış olup, bunlarda üst ekstremite morbiditesi olarak en sık \%45,5 oranla omuz ağrısı saptanmıştır. Diğer çalışmalarda da omuz ağrısı en sık yakınma olup \%38,5-73 arasında değişen oranlarda bulunmuştur $(7-9,11,25)$. Oranların yüksek çıkma nedeni bizim çalışmamızda da olduğu gibi değerlendirme parametresi olarak GAS kullanılması ve GAS>0'ın alınması olabilir. Çünkü literatürdeki ağrı ortalama skorları da 1,7-2,5 $(7,9)$ arasında saptanmış olup çalışmamızdaki 1,8 GAS ortalaması gibi düşük değerlere sahiptir.

Omuz ağrısı şiddeti ile hastanın yaşı, çıkarılan lenf nodu sayısı, KT alımı arasında ilişki saptanırken (25), operasyon tipi, hastalık evresi ve RT uygulanımı arasında ilişki saptanmamıştır (25-27). Çalışmamızda da omuz ağrısı ile hastalık evresi, RT, KT, yaş, operasyon tipi arasında ilişki saptanmadı. Bazı çalışmalarda yaşın omuz ağrısı ile ilişkisiz olduğu da bildirilmiştir $(26,27)$.

Ağrı ve omuzda hareket kısıtlılığı birbiriyle ve lenfödem varlığı ile ilişkili olabileceği gibi bağımsız olarak da karşımıza çıkabilmektedir (15). Armer ve ark.'nın (28) çalışmasında ağrı ve eklem hassasiyeti lenfödem varlığından bağımsız ortaya çıkan en sık semptomlar olarak belirtilmiştir. Hasta grubumuzda da bu 3 semptomun birbiriyle ilişkisi saptanmamıştır.

Koldaki şişliğin değerlendirilmesinde farklı teknikler ve eşik değerler kullanıldığı için (çevresel ölçüm, volümetrik ölçüm metodu, subjektif şişlik hissi gibi) lenfödem oranı \%10-45,6 gibi geniş bir aralıkta karşımıza çıkmaktadır $(7,9-11,13,15,22,23)$. Biz çalışmamızda çevresel ölçümle değerlendirme yaptığımızda lenfödem prevalansını \%34,8 oranında saptadık.

Cerrahi ile hasarlanan ana aksiller lenf damarlarının yerini alan sefalik lenf damarlarının postradyoterapi fibrozis nedeniyle hasarlanması kolun yetersiz lenfatik drenajıyla sonuçlanmaktadır. Bu nedenle RT, lenfödem gelişiminde bağımsız bir faktör olarak bulunurken, lenf nodu tutulumu olan hastalarda RT uygulanması nedeniyle tek başına lenf nodu pozitifliğini bağımsız faktör olarak değerlendirmek güçtür (29). Lenfödemin RT ve lenf nodu tutulumuyla olan yakın ilişkisini hasta grubumuzda değerlendirdiğimizde bu 2 faktörün diğer pek çok çalışmada olduğu gibi lenfödem varlığı ile ilişkili olduğunu saptadık $(29,30)$. Lenfödem ile ilişkili diğer faktörler yapılan çalışmalarda yüksek VKI $\left(\geq 25 \mathrm{~kg} / \mathrm{m}^{2}\right)$, KT alma ve hastalık evresi olarak sıralanabilir ki hasta grubumuzda da lenfödem ile yakın ilişkileri bulunmuştur $(29,30)$. Hastalık evresi arttıkça uygulanan tedavi şekillerinin de artmasıyla lenfödem gelişiminin arttığını varsaymaktayız. VKì ve lenfödem arasındaki ilişkinin ardındaki patofizyolojik mekanizma açık değildir. Yağ birikmesi zaten hasarlı olan lenfatik sisteme fazladan yük vererek ya da lenfatik drenajı bozarak lenfödemi arttırabilmektedir (29). Operasyon tipi ve dominant kol tutulumu irdelendiğinde ise çalışma grubumuzda lenfödem ile ilişkileri saptanmamıştır. van der Veen ve ark. (29) yaptığı çalışmada, lenfödem dominant kol tutulumu ile ilişkili iken operasyon tipi ve hastalık evresi ile ilişkili bulunmamıştır. Dominant elin günlük aktivitelerde sıklıkla kullanımı ve kolun aşırı zorlanması kapiller filtrasyonu arttırarak kolda ödemi tetikleyebileceğini bildirmişlerdir. Swenson ve ark. (30) ise operasyon tipinin (mastektomi) lenfödem üzerine etkili olduğunu bildirmiştir. Tüm bu verilere ters olarak Beaulac ve ark. (16) lenfödem olan ve olmayan hastalar arasında yaş, hastalık evresi, operasyon tipi (mastektomi-lumpektomi), RT, KT açısından fark bulmadıklarını bildirmişlerdir.

Çalışmamızda omuz eklem hareket kısıtlılığı \%22 oranla en az karşılaşılan yakınma olarak saptanmıştır. Bu oran literatürde \%1433,8 olarak belirtilmiştir $(7,9-11,13,22)$. Kontralateral taraf ile karşılaştırıldığında eklem hareket açıklığında 10-25 derecelik azalmanın hastaların günlük yaşamlarını etkilemediği gösterilmiştir $(14,31)$. Bu nedenle kontralateral ekstremite ile 25 derece ve üzeri fark olan hastalarımız omuz kısıtlılı̆ı pozitif olarak kaydedilmiştir (14). Omuz hareket kısıtlılı̆ı, uygulanan cerrahinin genişliği, sinir hasarı ve RT uygulaması nedeniyle meydana gelebilmektedir. Meme koruyucu cerrahi uygulanan hastalara göre mastektomi uygulanan hastalarda eklem hareket açıklığında daha fazla olan azalma cerrahi genişliğin disfonksiyona katkısına örnektir. Bu muhtemelen omuz stabilitesi ve mobilitesi için önemli kasların mastektomi sırasında eksizyonundan kaynaklanmaktadır. Pektoral, uzun torasik ve torakodorsal sinirlerin hasarı sırasıyla pektoral kasların atrofisi, kanat skapula ve latissimus dorsi kasının atrofisine neden olabilmektedir. RT sonrası hareket kısıtılığı, subkutan fibrozis nedeniyle derin kaslara olan fiksasyon sonucunda oluşabilmektedir (32). Rietman ve ark. (9) RT ve KT'nin, Kuehn ve ark. (13) ise KT'nin omuz eklem hareket açıklığı üzerine olumsuz etkileri olduğunu belirtmişlerdir. Beaulac ve ark. (16) ise azalmış eklem hareket açıklığına lenfödemin neden olduğunu öne sürmüştür. Bizim çalışmamızda lenfödem, omuz ağrısı ve diğer faktörlerle omuz hareket kısıtlıı̆ı arasında ilişki saptanmamıştır.

Meme kanserinde egzersiz adjuvan tedavi sırasında destekleyici bir yaklaşım olarak değerlendirilmektedir. Egzersiz

Tablo 4. Hastalarda lojistik regresyon analiziyle etkenlerin yaşam kalitesi alt alanlarını düşürme yönündeki etkileri.

\begin{tabular}{|c|c|c|c|c|c|c|c|}
\hline & Değişker & & B & S.E. & Anlamlilık & OR & $\% 95 G A$ OR \\
\hline Bedensel alan & Kısıtlılık & $\begin{array}{l}\text { var } \\
\text { yok }\end{array}$ & 1,370 & 0,585 & 0,019 & $\begin{array}{l}3,93 \\
1\end{array}$ & $1,24-12,39$ \\
\hline Ruhsal alan & Ağrı & $\begin{array}{l}\text { var } \\
\text { yok }\end{array}$ & 1,123 & 0,404 & 0,005 & $\begin{array}{l}3,07 \\
1\end{array}$ & $1,39-6,78$ \\
\hline Çevre alanı & Egzersiz & $\begin{array}{l}\text { var } \\
\text { yok }\end{array}$ & $-1,211$ & 0,472 & 0,010 & $\begin{array}{l}0,29 \\
1\end{array}$ & $0,11-0,75$ \\
\hline
\end{tabular}

OR: Odds Ratio, SE:Standard Error, B:Regresyon katsayıSI 
fiziksel uyumu arttırarak günlük yaşam aktivitelerini yerine getirme kapasitesini arttırmaktadır (33). Sagen ve ark. (34) aksiller lenf diseksiyonlu hastaların hiçbir kısıtlamaya gitmeksizin ve lenfödem gelişme korkusu yaşamaksızın günlük yaşantısında kollarını kullanmaya devam etmelerini önermişlerdir. Çalışmamızda egzersiz yapan yani opere taraf eklem hareket açıklığı egzersizlerini düzenli uygulayan hastalarda egzersizin her üç semptom üzerine olumlu yönde etkilerinin olduğu görülmüştür. Egzersizin omuz tam hareket açıklığını sağlamak, omuz disfonksiyonuyla ilişkili morbiditeyi ve lenfödem gelişimini azaltmak için başlanması önerilmektedir (35).

Üst ekstremite morbiditesinin yaşam kalitesi üzerine olumsuz etkisi birçok çalışmada gösterilmiştir. Kwan ve ark.'nın (3) yaptığı çalışmada ağrı, lenfödem ve omuz hareket kısıtlılığı olan üst ekstremite morbiditeli hastalarda EORTC QLQ C-30 yaşam kalitesinin fiziksel, sosyal ve ağrı semptom alt skorlarında asemptomatik hastalara göre belirgin bozukluk bulunmuştur.

Beaulac ve ark. (16) yaşam kalitesi olarak FACT-B ölçeğini kullandıklarında, operasyon tipi, hastalık evresi, KT, yaş, operasyon sonrası geçen süre ile total FACT-B skor arasında anlamlı ilişki bulmadıklarını bildirmişlerdir. Lenfödem, omuz hareket kısıtlılığı, yüksek VKI $\left(\geq 25 \mathrm{~kg} / \mathrm{m}^{2}\right)^{\prime}$ nin total FACT-B skor, memede iyi olma hali, fonksiyonel iyi olma hali, fiziksel iyi olma hali üzerine olumsuz etkisi bulunurken, sosyal iyi olma hali üzerine etkisi bulunmamıştır. Lenfödemin ayrıca emosyonel iyi olma hali üzerine de olumsuz etkisi görülmüştür. Yaşam kalitesi için en önemli faktörün araştırılması amacıyla yapılan analizde lenfödemin yaşam kalitesi üzerine olumsuz etkisi bulunan en önemli faktör olduğu bildirilmiştir. Tam tersine Kaya ve ark. (7) FACT-B+4 versiyonu ile yaptıkları çalışmalarında lenfödemin yaşam kalitesi ölçeğinin tüm alt gruplarında olumsuz etkisinin olmadığını saptamışlardır. Fiziksel iyi olma hali, emosyonel iyi olma hali, fonksiyonel iyi olma hali, meme kanser subskalası ve kol subskalası alt gruplarına sahip olan FACT-B+4 yaşam kalitesi ölçeğinde, kol morbiditesine neden olan omuz hareket kısıtlılığının $\left(\geq 20^{\circ}\right)$ emosyonel ve fonksiyonel iyi olma hali alt gruplarını daha çok etkilediği, omuz hareket ağrısının ise kol subskalasını daha çok etkilediği gösterilmiştir.

Benzer şekilde Nesvold ve ark. (14) omuzda kısıtlılık $\left(\geq 25^{\circ}\right)$, lenfödem $(\geq 2 \mathrm{~cm})$, omuz-kol problemlerinin kendi bildirimini içeren 3 problemden ikisini ve/veya üçünü içeren grubu kol-omuz problemli grup olarak kabul etmiş ve bu grubun problemi olmayan gruba göre SF-36'nın tüm alt gruplarında anlamlı olarak daha kötü sonuçlar gösterdiğini belirtmişlerdir. SF-36'nın alt gruplarında lenfödem ve omuzda hareket kısıtlılı̆ı göz önüne alınıp hangisinin daha fazla olumsuz etkiye sebep olduğuna bakıldığında, fiziksel ve mental alt gruplarının hepsinin anlamlı derecede azalmış omuz abduksiyon hareket açıklığı ile ilişkili olduğu saptanırken, lenfödemin yaşam kalitesi alt parametreleri üzerine anlamlı ilişkisi gösterilememiştir.

Rietman ve ark. (9) RAND-36'yı kullandıkları yaşam kalitesi değerlendirmesinde omuz ağrısının (GAS>0), yaşam kalitesinin 6 alt grubunu (sosyal fonksiyon, mental sağlık, vitabilite, ağrı, sağlık algısı, sağlık değişikliği) etkileyen en önemli faktör olduğunu, buna karşılık lenfödemin (volümetrik ölçüm) 2 (fiziksel fonksiyon, fiziksel rol kısıtlanması), kısıtlılığın $\left(\geq 20^{\circ}\right) \quad 1$ (fiziksel fonksiyon) alt grubu etkilediğini göstermişlerdir. Meme kanseri cerrahisi sonrası ağrı, kanserin rekürrensi veya progresyonu olarak algılandığı için hastaların hem fiziksel hem de mental sağlığını etkileyerek hayat kalitesinin bozulmasına neden olduğu bildirilmektedir (8).
Bizim çalışmamızda opere meme kanserli hastalar WHOQOLBREF TR ile değerlendirilmiş ve lenfödem, ağrı ve omuz hareket kısıtııı̆ının bedensel, ruhsal alt alanların tümü ile ilişkili olduğu, omuz hareket kısıtlıığının ayrıca çevre alt alanı üzerinde etkili olduğu gösterilmiştir. Kol morbiditesini temsil eden bu 3 semptomatolojinin hangisinin yaşam kalitesi üzerine daha etkili olduğuna baktığımız lojistik regresyon analizinde omuz ağrısının bedensel ve ruhsal alana, kısıtlılığın bedensel alan üzerine en etkili olduğu, lenfödemin ise yaşam kalitesi alt alanlarında etkisinin olmadığı gösterilmiştir. Ayrıca egzersizin ruhsal alan ve çevre alanı üzerine olumlu katkısı bulunmuştur. WHOQOL-BREF TR sosyal alt alanında omuz ağrısı, hareket kısıtlılığı ve lenfödemin herhangi bir etkisinin olmadığı gözlenmiştir. Oysa sosyal alan sorularından olan cinsel fonksiyonun; meme kanseri tedavisine sekonder olarak gelişen seks hormonu eksikliği ve vücut imajındaki bozukluk sonucu, libidoda azalma, lubrikasyonda azalma/disparoni, anorgazmi nedeniyle bozulması beklenmektedir (36). Hastalarımızın cinsel yaşamdan memnuniyet sorgulamasında düşüklük olsa da yüksek sosyal destek almaları nedeni ile sosyal alan alt grubunda beklenen bozukluğun saptanmadığı kanaatindeyiz.

Çalışmamız kesitsel bir çalışma olduğundan hasta grubumuzun meme cerrahisi sonrası geçen sürelerinin farklılıklar göstermesi kısıtlılığı olarak düşünülmüştür. Mevcut ve yeni hastaların takipleri ile sorunların ortaya çıkma süreçlerinin ve seyirlerinin belirlenmesinin gerektiği inancındayız.

Meme cerrahisi öncesi veya hemen sonrası olası üst ekstremite problemlerinin hastaya anlatılması, koruyucu önlemlerin alınması ve düzenli takip ile komplikasyonların en aza indirilerek hastaların yaşam kalitesinin korunması tüm rehabilitasyon alanlarında olduğu gibi bu hastaların yaklaşımında da temel hedef olmalıdır.

\section{Çıkar Çatışması:}

Yazarlar herhangi bir çıkar çatışması bildirmemişlerdir.

\section{Kaynaklar}

1. Morrell RM, Halyard MY, Schild SE, Ali MS, Gunderson LL, Pockaj BA. Breast cancer-related lymphedema. Mayo Clin Proc 2005;80:1480-4.

2. Engel J, Kerr J, Schlesinger-Raab A, Sauer H, Hölzel D. Axilla surgery severely affects quality of life: results of a 5 -year prospective study in breast cancer patients. Breast Cancer Res Treat 2003;79:47-57.

3. Kwan W, Jackson J, Weir LM, Dingee C, McGregor G, Olivotto IA. Chronic arm morbidity after curative breast cancer treatment: prevalence and impact on quality of life. J Clin Oncol 2002;15;20:4242-8.

4. Norman SA, Localio AR, Potashnik SL, Simoes Torpey HA, Kallan MJ, Weber $\mathrm{AL}$, et al. Lymphedema in breast cancer survivors: incidence, degree, time course, treatment, and symptoms. I Clin Oncol 2009;20;27:390-7.

5. Herd-Smith A, Russo A, Muraca MG, Del Turco MR, Cardona G. Prognostic factors for lymphedema after primary treatment of breast carcinoma. Cancer 2001;92:1783-7.

6. Paskett ED, Naughton MJ, McCoy TP, Case LD, Abbott JM. The epidemiology of arm and hand swelling in premenopausal breast cancer survivors. Cancer Epidemiol Biomarkers Prev 2007;16:775-82.

7. Kaya T, Karatepe AG, Günaydn R, Yetiş H, Uslu A. Disability and healthrelated quality of life after breast cancer surgery: relation to impairments. South Med J 2010;103:37-41.

8. Caffo O, Amichetti M, Ferro A, Lucenti A, Valduga F, Galligioni E. Pain and quality of life after surgery for breast cancer. Breast Cancer Res Treat 2003;80:39-48.

9. Rietman JS, Dijkstra PU, Debreczeni R, Geertzen JH, Robinson DP, De Vries । Impairments, disabilities and health related quality of life after treatment for breast cancer: a follow-up study 2.7 years after surgery. Disabil Rehabil 2004;21;26:78-84. 
10. Keramopoulos A, Tsionou C, Minaretzis D, Michalas S, Aravantinos D. Arm morbidity following treatment of breast cancer with total axillary dissection: a multivariated approach. Oncology 1993;50:445-9.

11. Maunsell E, Brisson ], Deschênes L. Arm problems and psychological distress after surgery for breast cancer. Can I Surg 1993;36:315-20.

12. Velanovich V, Szymanski W. Quality of life of breast cancer patients with lymphedema. Am J Surg 1999;177:184-7.

13. Kuehn T, Klauss W, Darsow M, Regele S, Flock F, Maiterth C, et al. Long-term morbidity following axillary dissection in breast cancer patients-clinical assessment, significance for life quality and the impact of demographic, oncologic and therapeutic factors. Breast Cancer Res Treat 2000;64:275-86.

14. Nesvold IL, Fosså SD, Holm I, Naume B, Dahl AA. Arm/shoulder problems in breast cancer survivors are associated with reduced health and poorer physical quality of life. Acta Oncol 2010;49:347-53.

15. McCredie MR, Dite GS, Porter L, Maskiell J, Giles GG, Phillips KA, et al. Prevalence of self-reported arm morbidity following treatment for breast cancer in the Australian Breast Cancer Family Study. Breast 2001;10:515-22.

16. Beaulac SM, McNair LA, Scott TE, LaMorte WW, Kavanah MT. Lymphedema and quality of life in survivors of early-stage breast cancer. Arch Surg 2002;137:1253-7.

17. Delialioğlu SÜ, Aras MD, Yiğit Z. Lenfödem ve tedavisi. Turkiye Klinikleri J Int Med Sci 2006;2:49-58.

18. Eser E, Fidaner H, Fidaner C, Eser SY, Elbi H, Göker E. WHOQOL-100 ve WHOQOL-BREF'in psikometrik özellikleri. 3P Dergisi 1999;7:23-40.

19. Eser SY, Fidaner $H$, Fidaner $C$, Elbi H, Eser E, Göker E. Yaşam kalitesinin ölçülmesi, WHOQOL-100 ve WHOQOL-BREF. 3P Dergisi 1999;7(2):5-13.

20. Centers for Disease Control and Prevention (CDC). Cancer survivorship-United States, 1971-2001. MMWR Morb Mortal Wkly Rep 2004;53:526-9.

21. Lee TS, Kilbreath SL, Refshauge KM, Herbert RD, Beith JM. Prognosis of the upper limb following surgery and radiation for breast cancer. Breast Cancer Res Treat 2008;110:19-37.

22. Ivens $\mathrm{D}$, Hoe AL, Podd TI, Hamilton CR, Taylor I, Royle GT. Assessment of morbidity from complete axillary dissection. Br J Cancer 1992;66:136-8.

23. Kissin MW, Querci della Rovere G, Easton D, Westbury G. Risk of lymphoedema following the treatment of breast cancer. $\mathrm{Br}$ । Surg 1986;73:580-4.
24. Lin PP, Allison DC, Wainstock J, Miller KD, Dooley WC, Friedman N, et al. Impact of axillary lymph node dissection on the therapy of breast cancer patients. / Clin Oncol 1993;11:1536-44.

25. Hack TF, Cohen L, Katz J, Robson LS, Goss P. Physical and psychological morbidity after axillary lymph node dissection for breast cancer. J Clin Oncol 1999;17:143-9.

26. Tasmuth T, von Smitten K, Kalso E. Pain and other symptoms during the first year after radical and conservative surgery for breast cancer. Br J Cancer 1996;74:2024-31.

27. Sugden EM, Rezvani M, Harrison JM, Hughes LK. Shoulder movement after the treatment of early stage breast cancer. Clin Oncol (R Coll Radiol) 1998; 10:173-81.

28. Armer J, Fu MR. Age differences in post-breast cancer lymphedema signs and symptoms. Cancer Nurs 2005;28:200-7.

29. van der Veen P, De Voogdt N, Lievens P, Duguet W, Lamote J, Sacre R. Lymphedema development following breast cancer surgery with full axillary resection. Lymphology 2004;37:206-8.

30. Swenson KK, Nissen M], Leach JW, Post-White J. Case-control study to evaluate predictors of lymphedema after breast cancer surgery. Oncol Nurs Forum 2009;36:185-93.

31. Tengrup I, Tennvall-Nittby L, Christiansson I, Laurin M. Arm morbidity after breast-conserving therapy for breast cancer. Acta Oncol 2000;39:393-7.

32. Gomide LB, Matheus JP, Candido dos Reis FJ. Morbidity after breast cancer treatment and physiotherapeutic performance. Int I Clin Pract 2007;61:972-82.

33. Başaran $S$, Kozanoğlu E. Meme kanseri ile ilişili lenfödem ve konservatif tedavisi. Türk Fiz Tıp Rehab Derg 2009;55:29-34.

34. Sagen A, Kåresen R, Risberg MA. Physical activity for the affected limb and arm lymphedema after breast cancer surgery. A prospective, randomized controlled trial with two years follow-up. Acta Oncol 2009;48:1102-10.

35. Todd J, Topping A. A survey of written information on the use of postoperative exercises after breast cancer surgery. Physiotherapy 2005;91:8793.

36. Brédart A, Dolbeault S, Savignoni A, Besancenet C, This P, Giami A, et al. Prevalence and associated factors of sexual problems after early-stage breast cancer treatment: results of a French exploratory survey. Psychooncology 2011;20:841-50. 